\title{
The Emerging Potential of Advanced Targeted Mass Spectrometry to Become a Routine Tool for Protein Quantification in Biomedical Research
}

\author{
Minia Antelo Varela and Alexander Schmidt*
}

\begin{abstract}
Mass spectrometry-based proteomics has become an indispensable tool for system-wide protein quantification in systems biology, biomedical research, and increasingly for clinical applications. In particular, targeted mass spectrometry offers the most sensitive and reproducible quantitative detection of proteins, peptides and post-translational modifications of any currently applied mass spectrometry technique and is therefore ideally suited to generate high quality quantitative datasets. Despite these apparent advantages, targeted mass spectrometry is only slowly gaining popularity in academia and pharmaceutical industries, mainly due to the additional efforts in assay generation and manual data validation. However, with the increasing accumulation of mass spectrometry data, advances in deep learning spectral prediction for automated assay development, these obstacles can and will be considerably reduced in the near future. Here, we describe the latest technological developments in this field and discuss the emerging importance of targeted mass spectrometry for systems biology research and potential key roles in bridging biomedical discovery and clinical implementation.
\end{abstract}

Keywords: DIA · Parallel reaction monitoring $\cdot$ Selected reaction monitoring $\cdot$ SureQuant $\cdot$ Targeted mass spectrometry · TOMAHAQ

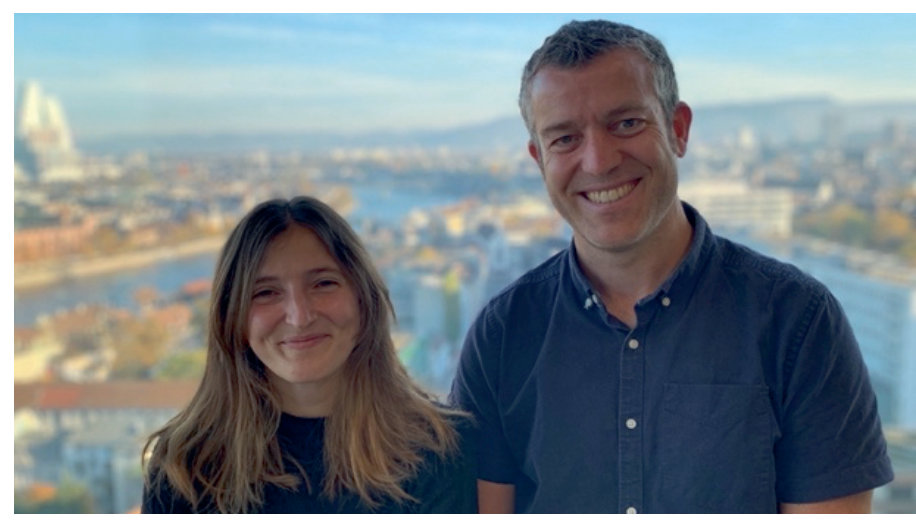

Minia Antelo Varela (left), graduated from the University of Lisbon in Molecular Biology and Genetics (Portugal) in 2011, where she also completed her masters in Applied Microbiology in 2014. She completed her PhD in 2019 as part of a Marie Curie ITN in the Microbial Proteomics group of the University of Greifswald (Germany), where she developed mass spectrometry-based methods for absolute membrane protein quantification. In 2020 she started her post-doc in Bumann's group at the Biozentrum (University of Basel, Switzerland) as part of the NCCR - AntiResist, where she is developing quantitative mass spectrometry approaches for the characterization of pathogens in clinical samples.

Alexander Schmidt (right), graduated from the University of Erlangen-Nuremberg (Germany) in analytical chemistry in 2001, followed by his $\mathrm{PhD}$ in Biochemistry in 2006 at the Max-Planck Institute of Biochemistry in the Protein Analytics Group of Dr.

*Correspondence: Dr. A. Schmidt, E-mail: alex.schmidt@unibas.ch,

Biozentrum, University of Basel, Spitalstrasse 41, CH-4056 Basel, Switzerland
Friedrich Lottspeich (Munich, Germany). In 2006, he joined the group of Ruedi Aebersold as a Post-doc and developed sensitive targeted mass spectrometric approaches for biomarker and proteoform quantification. Since December 2009, he is heading the Proteomics Core Facility of the Biozentrum at the University of Basel (Switzerland). He is continuing to develop new quantitative mass spectrometric methods for biomedical and systems biology applications.

\section{Introduction}

Mass spectrometry (MS)-based proteomics has become the preferred technique for proteome and proteoform profiling at a system-wide scale. ${ }^{[1,2]}$ It is now routinely used in biomedical research for novel biomarker discovery, ${ }^{[3-5]}$ and, in combination with genomics approaches, improved patient classification as well as better understanding of molecular disease mechanisms, in particular in cancer. ${ }^{[6,7]}$ Most of the proteome wide screens to date rely on data-dependent acquisition approaches (DDA), in which the most abundant precursor ions are selected for MS-sequencing. Even though this technique is capable of providing a good sample overview, the acquisition speed of current MS systems is not sufficient to sequence all detected precursor ions. Consequently, the acquired data is biased towards the most abundant peptide ions, thereby dismissing low abundant proteoforms across large sample cohorts. In addition, DDA suffers from poor quantification precision, a result of the stochastic selection of precursor ions for MS-sequencing. ${ }^{[8,2]}$ Therefore, DDA LC-MS approaches do not meet the requirements for confident quantification of, typically low abundant, protein biomarkers across large clinical sample cohorts. ${ }^{[10]}$

Conversely, more recently developed data-independent acquisition (DIA) approaches, initially proposed by the Yates group in 2004[11] and then further developed by the Aebersold group in 2012 , ${ }^{[9]}$ triggered by the introduction of high-resolution/accurate mass (HR/AM) MS instrumentation, hold great promise to over- 
come these limitations and to become reliable tools for routine clinical proteome analyses. In contrast to DDA, MS/MS fragmentation in DIA is not randomly focused on the most abundant precursor ions but on pre-defined mass-to-charge $(\mathrm{m} / \mathrm{z})$ windows. This allows the generation of reproducible and consistent data sets across samples. DIA approaches can be grouped in the following three categories (Fig. 1): selected reaction monitoring (SRM), also known as multiple reaction monitoring (MRM); ${ }^{[12-14]}$ parallel reaction monitoring $(\mathrm{PRM})^{[15,16]}$ and standard DIA, also known as SWATH ${ }^{[9]}$ or hyper reaction monitoring (HRM) MS, ${ }^{[17]}$ here referred to as SWATH. The methods differ in their pre-defined precursor and product ion $\mathrm{m} / \mathrm{z}$ isolation window setting. The $\mathrm{m} / \mathrm{z}$ windows can either be set very narrowly (usually $0.4-1.4 \mathrm{~m} / \mathrm{z}$ ) for the specific quantitative analysis of pre-selected peptide ions of interest using SRM and PRM (Fig. 1), or wider (usually 8-25 m/z, depending on the scan speed of the MS platform employed) to generate overlapping, staggered mass windows that cover the entire peptide ion $\mathrm{m} / \mathrm{z}$, range (usually $400-1000 \mathrm{~m} / \mathrm{z}$ ) allowing discovery-based proteome analysis using SWATH (Fig. 1).
More recently, HR/AM MS platforms, mostly Orbitrap and QqTOF systems, are increasingly used for targeted MS. In contrast to SRM, the HR/AM analyzer acquires a full MS/MS spectrum of all generated fragment ions of the selected precursor. Since all fragments/transitions are acquired at the same time within one spectrum, this targeted MS method is termed parallel reaction monitoring ${ }^{[15,16]}$ (PRM, Fig. 1). Compared to SRM, the generation of HR/AM transitions allows the application of much smaller $\mathrm{m} / \mathrm{z}$ isolation windows at the MS2 level, increased overall selectivity and identification confidence in complex human cell lysates by almost two orders of magnitude. [15] Thus, PRM assays can reach detection limits directly from complex samples that are currently only available with antibody-based techniques, like ELISA. ${ }^{[18,19]}$ For this sensitive quantification of low abundant proteoforms within complex samples, however, PRM requires maximal ion accumulation times and highest MS2 resolution settings, allowing only a few peptide ions to be included per MS run. ${ }^{[20]}$ By contrast, QqQ instruments provide higher sensitivity and speed over PRM, making it better suited for the analysis of less complex samples and more targets.

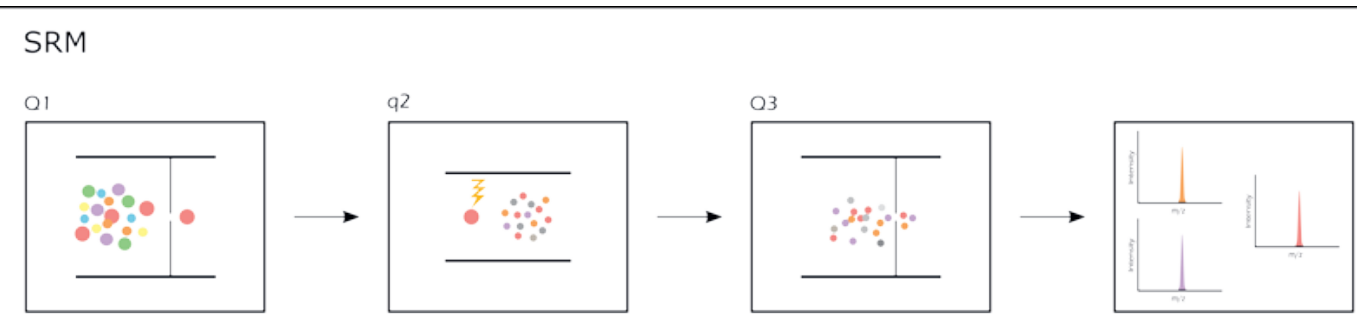

PRM

01
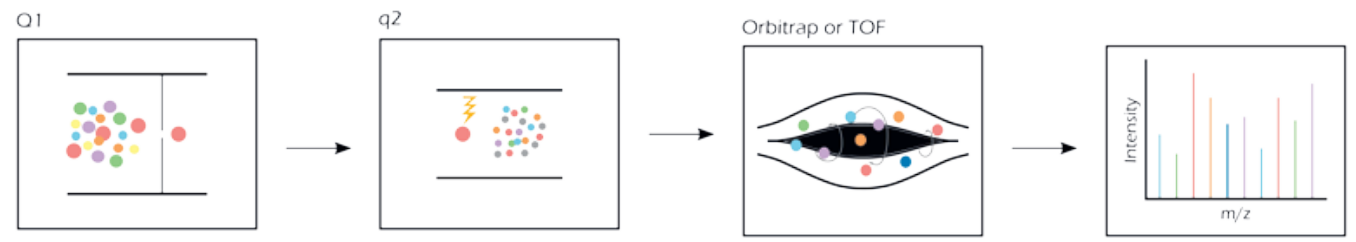

SWATH

01

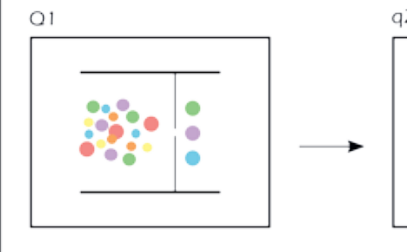

q2

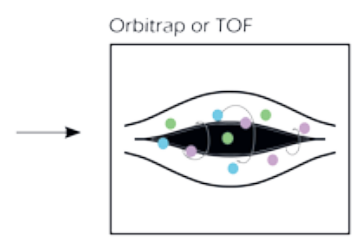

Fig. 1. Overview of current dataindependent acquisition MS methods. In selected-reaction monitoring (SRM) MS, the precursor ion of a preselected target peptide is selected in the first quadrupole (Q1) and further transferred for fragmentation in the collision cell (q2). The generated product ions of the target peptide are selected for detection on the third quadrupole (Q3). Parallel reaction monitoring (PRM) MS is very similar to SRM MS, however, a tandem mass spectrum of all fragment ions is acquired by a high-resolution (usually time-of-flight (TOF) or Orbitrap) mass analyser. In SWATH, all peptide ions within a defined mass-to-charge $(\mathrm{m} / \mathrm{z})$ window are isolated in Q1, fragmented together in the collision cell (q2), and the generated product ions are monitored by a highresolution mass analyser. The process is progressively iterated across the entire peptide precursor ion mass range.
While SWATH analysis is exclusively carried out on HR/AM instruments, SRM/MRM can be performed on relatively cheap, low resolution triple quadrupole instruments (QqQ, Fig. 1), a quantitative MS strategy originally designed for the analysis of small molecules. Here, the first quadrupole (Q1) is set to a very narrow $\mathrm{m} / \mathrm{z}$ window of typically $0.7 \mathrm{~m} / \mathrm{z}$, to isolate a defined precursor ion of a peptide of interest. After fragmentation in the collision cell (q2), the third quadrupole (Q3) is set to a narrow $\mathrm{m} / \mathrm{z}$ window to isolate a specific product ion of this particular peptide ion. This entire process is also termed transition. Five different transitions are usually used for confident peptide ion quantification. Due to the narrow windows of $0.7 \mathrm{~m} / \mathrm{z}$ employed for both precursor and fragment ion, the SRM approach is highly selective and provides a high dynamic quantification range.
Notably, SRM and PRM analyses are typically combined with stable isotope dilution (SID) techniques boosting target quantification confidence and reproducibly ${ }^{[21]}$ Here, heavy internal standard (IS) peptides are spiked into the samples and analyzed together with their endogenous derived counterparts, even allowing absolute protein quantification ${ }^{22]}$ SID-SRM provides superior sensitivity and dynamic range over DDA MS for the analysis of low abundant proteins ${ }^{[23]}$ and, most importantly, a higher quantitative reproducibility within large sample sets and across different laboratories when sharing generated SRM assays, ${ }^{[24]}$ demonstrating the suitability of SRM for clinical applications. Being in nature focused on selected targets, SRM or PRM cannot be employed for discovery driven unbiased proteome analysis. This triggered the 
development of SWATH workflows allowing reproducible proteome wide quantitative analysis. The SWATH approach was first developed by the Yates laboratory in 2004 using low resolution instrumentation, ${ }^{[11]}$ followed by its application to HR/AM MS in 2012 by the Aebersold group. ${ }^{[9]}$ Since then, SWATH popularity soared and the approach was continuously improved, particularly on the data analysis side. ${ }^{[25-27]}$ Since SWATH data analysis requires a spectral reference library to assign the eluting fragments to peptide sequences, data analysis was not as straightforward compared to sequence database searching in DDA. However, with the introduction of high-quality tandem mass spectra prediction machine learning algorithms and software, SWATH data can now be also reliably and comprehensively searched directly from sequence database files. ${ }^{[28-30]}$ This not only considerably facilitates SWATH data analysis, but also improves the reproducibility and evaluation of the results by other laboratories. It also enables the straightforward quantification of rare proteoforms and protein modifications lacking reference spectra. ${ }^{[31]}$ As SRM, SWATH has also shown to overcome many reproducibility and robustness limitations of DDA and is now widely and increasingly used by the proteomics community, in particular for clinical sample analyses. ${ }^{[32-34]}$ Nonetheless, owing to the larger $\mathrm{m} / \mathrm{z}$ windows required to scan the entire mass range within one MS cycle and the resulting shorter dwell time for individual peptide ions, sensitivity, selectivity and reproducibility lags behind targeted SRM/PRM approaches. ${ }^{[9]}$

There are exciting new developments in the SWATH based discovery proteome analysis field, however, including those would be beyond the scope of this review. We therefore only focus on the latest developments in targeted MS. This mainly includes (i) boosting the sensitivity of (mostly SRM) assays by enriching target concentrations within samples before targeted MS analysis and (ii) novel targeted MS concepts (mostly PRM) enabling more intelligent MS2 acquisition and thereby considerably elevating multiplexing capabilities. We assess and discuss the potential and limitations of these next generation targeted MS approaches for proteomics applications and its impact on biomedical, system biology and basic life science research. However, it should be noted that the corresponding publications utilizing these various approaches largely differ in required MS instrumentation, sample preparation workflows and applications making an unbiased comparison and general recommendations challenging. In this review, we aim to provide a thorough overview of the general strengths and weaknesses of the current and most promising next generation targeted MS concepts (Fig. 2). We hope this provides useful information for planning and selecting the most suited targeted MS approaches.

\section{Increasing Sensitivity of Targeted Assays}

SRM has been demonstrated to provide excellent performance and reproducibility in general paired with very high multiplexing capabilities $^{[24]}$ (Fig. 2), however, its selectivity and sensitivity remains limited and insufficient for full dynamic range analysis of complex peptide samples, like eukaryotic proteomes. ${ }^{[15]}$ Since the selectivity in SRM is set by the (low) resolution of the QqQ instrument employed, several sample preparation techniques have been developed that increase the concentration of the SRM targets in the sample and thus elevate the overall sensitivity of the SRM assays. While mostly applied for SRM assays, these front-end sample preparation techniques work equally well with other targeted MS platforms and approaches. We will highlight two popular and conceptionally different target enrichment strategies using either affinity purification or extensive sample fractionation.

\subsection{Affinity Enrichment}

Enrichment of specific peptides by immunoaffinity purification using antibodies prior to SRM analysis improves the sensitivity and performance of the assay particularly in bodily fluids such as serum and plasma that are predominantly analyzed in clinical laboratories. The Stable Isotope Standards and Capture by Anti-Peptide Antibodies (SISCAPA) workflow enables the enrichment of target and spiked-in heavy reference peptides using
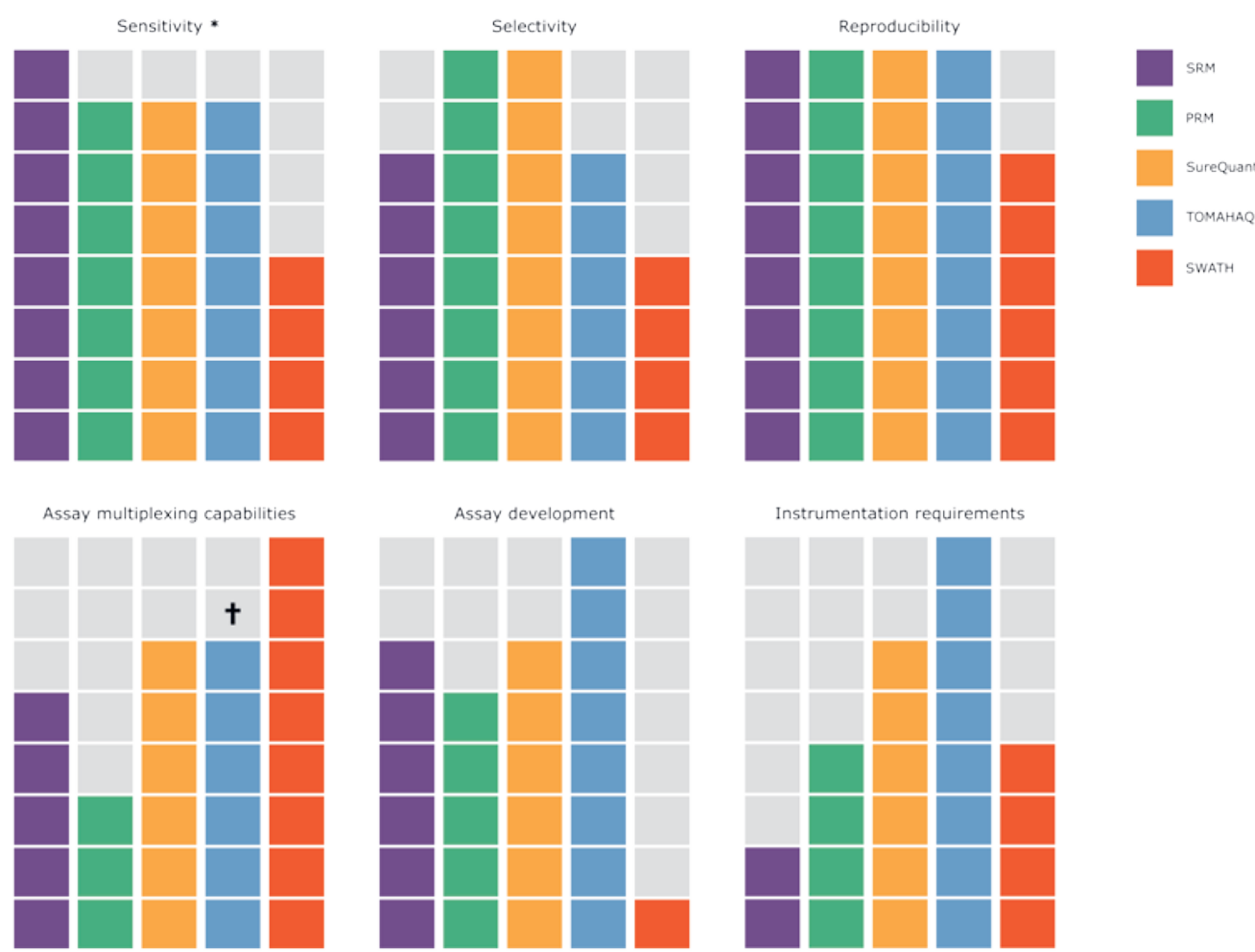

Fig. 2. Relative comparison of different analytical parameters between SRM, PRM, SureQuant, TOMAHAQ and SWATH MS. In the plots, each method is represented by a colored bar according to the analytical parameters. The color of each plot represents the relative magnitude of the variables. A fully coloured bar plot indicates the maximum value for a certain variable in comparison to the other acquisition methods. *Absolute values for most parameters are currently missing, however, LOD/LOQ values for each method are provide in Table 1. †Notably, the sample multiplexing capability of the TOMAHAQ approach provided by the employed TMT quantification is not considered in the assay multiplexing graph. 
anti-peptide antibodies. ${ }^{[35]}$ SISCAPA-based target enrichment in combination with SRM has been shown to be a powerful strategy to quantitate low abundant proteins in complex mixtures with high sensitivity and precision down to the low $\mathrm{ng} / \mathrm{mL}$ level in human and mouse plasma ${ }^{[36-39]}$ (Table 1). More recently, this sensitive technology was also employed for the detection and quantification of SARS-CoV-2 in clinical samples with low viral load. ${ }^{[40]}$ Lately, multiplexed SISCAPA enrichment preparations using a panel of peptide antibodies to purify tens of peptides from the same sample were employed to match the multiplexing capabilities of SRM and increase the number of quantified targets per LC-MS analysis. ${ }^{[41]}$ Further developments include using low cost and easy to produce recombinant antibody fragments (Fabs) instead of monoclonal antibodies post-translational modifications (PTMs), is a particular strength of targeted MS and can be employed to improve the functional readout of many existing immunoassays centered on the analysis of total protein abundances. ${ }^{[44]}$

More recently, specific SRM/PRM panels focusing on phospho-signaling pathways of interest have been developed and applied to study kinase signaling pathway activities in tumor cells and tissues. ${ }^{[45]}$ Here, phosphorylated peptides are affinity purified in two steps using (i) phospho-tyrosine antibody enrichment followed by (ii) immobilized metal affinity chromatography (IMAC) enrichment. Both samples are then individually analyzed and quantified by SID-SRM MS focusing on the key phosphorylation sites for pathway activity determination. Using

Table 1. Overview of selected applications of the different SID targeted MS methods discussed in this review.

\begin{tabular}{|c|c|c|c|c|c|}
\hline MS method & Sensitivity & $\begin{array}{l}\text { Number of } \\
\text { targets }\end{array}$ & MS system ${ }^{a}$ & Sample & Ref. \\
\hline SISCAPA-SRM & $\begin{array}{c}0.3-3 \mathrm{ng} / \mathrm{mL} \text { (LOD), } \\
2-10 \mathrm{pg} / \mathrm{mL} \text { (LOQ) }\end{array}$ & 3 proteins & QqQ & Plasma (human) & [39] \\
\hline PRISM-SRM & $0.5-5 \mathrm{ng} / \mathrm{mL}$ (LOQ) & 3 proteins & QqQ & Plasma (human) & {$[52]$} \\
\hline SRM & $\begin{array}{l}30 \text { attomole on column } \\
\text { (LOD) }\end{array}$ & 20 peptides & QqQ & $\begin{array}{l}\text { Cell lysate } \\
\text { (human) }\end{array}$ & [23] \\
\hline SRM & $0.5-2 \mu \mathrm{g} / \mathrm{mL}$ (LOQ) & 7-11 peptides & Qq-ion trap & Plasma (human) & [24] \\
\hline $\begin{array}{c}\text { Antibody } \\
\text { enrichment-PRM }\end{array}$ & 2-10 pg/mL (LOQ) & 3 peptides & QqOT & Plasma (human) & [18] \\
\hline PRM & $\begin{array}{l}\text { Low attomole range on } \\
\text { column (LOQ) }\end{array}$ & 21 peptides & QqOT & $\begin{array}{l}\text { Cell lysate } \\
\text { (human) }\end{array}$ & [20] \\
\hline TOMAHAQ & $\begin{array}{l}\text { 10-200 attomole on } \\
\text { column (LOQ) }\end{array}$ & 14 peptides & Tribrid system ${ }^{\mathrm{b}}$ & $\begin{array}{c}\text { Cell lysate } \\
\text { (human) }\end{array}$ & [75] \\
\hline SureQuant & $\begin{array}{l}10 \text { attomole on column } \\
\text { (LOD) }\end{array}$ & 18 peptides & Exploris QqOT & $\begin{array}{l}\text { Cell lysate } \\
\text { (human) }\end{array}$ & [68] \\
\hline
\end{tabular}

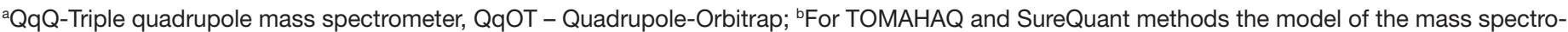
meter is specified because the methods are exclusively implemented in these mass spectrometers distributed by Thermo Fisher Scientific. Notably. SureQuant can also be performed on Tribrid systems.

for peptide enrichment ${ }^{[39]}$ and aptamers for protein enrichment. ${ }^{[42]}$

Besides the antibody enrichment at the peptide level, affinity purification of proteins using specific monoclonal antibodies shows less nonspecific binding and can handle a higher range of sample volumes allowing the analysis of very low abundant plasma proteins in combination with targeted MS down to the pg/mL range. ${ }^{[18,43]}$ Furthermore, protein-based enrichment allows to employ multiple targeted MS assays for protein quantification and also enables the precise and sensitive quantitation of specific proteoforms for which no antibodies exist. ${ }^{[18]}$ In the latter case, full length and therefore active CXCL10 could be specifically quantified down to the low $\mathrm{pg} / \mathrm{mL}$ level in plasma and demonstrated to be of greater clinical value than total CXCL10 levels currently determined by ELISA. For ELISA measurements, the inactivation of CXCL10 is triggered by a cleavage of the first two n-terminal amino acids by DPP4, a small truncation for which, so far, no specific antibodies could be generated. The precise and specific analysis of highly similar proteoforms, including small this 'SigPath' approach comprising SRM assays for 284 phosphosites in 200 phosphoproteins, around 80-120 phosphosites could be precisely and robustly monitored within different cell lines. ${ }^{[45]}$ It is also important to note that the success of this approach, like all affinity enrichment strategies, critically depends on high sample starting amounts to reach the required SID-SRM sensitivities.

\subsection{PRISM}

Antibody- or other affinity-based enrichment methods are excellent tools to increase target concentrations and thus the overall SRM assay sensitivity. However, especially for new proteins or highly similar proteoforms, like small PTMs or single amino acid variations, the availability of specific affinity binders for enrichment are limited. Therefore, a couple of antibody-free, sample pre-fraction techniques were developed to reduce sample complexity and increase SRM sensitivity. ${ }^{[46]}$ This includes SDSPAGE, ${ }^{[47]}$ removal of high abundant proteins in plasma using 
acetonitrile precipitation ${ }^{[48]}$ as well as nanoparticle protein coronas $^{[49]}$ and chromatography-based fractionation. ${ }^{[50,51]}$ The socalled high-pressure, high-resolution separations with intelligent selection and multiplexing (PRISM) approach ${ }^{[52]}$ employed the high and complementary peptide separation power of high $\mathrm{pH}$ reversed phase liquid chromatography ${ }^{[53]}$ to prepare and select target enriched fractions for SRM analysis based on the elution profiles of spiked in heavy reference peptides. This fully automated approach demonstrated, in combination with immunoaffinity depletion of the 14 most abundant plasma proteins, accurate and robust quantification of human plasma proteins down to the high $\mathrm{pg} / \mathrm{mL}$ range ${ }^{[52,54]}$ (Table 1). This technology can work with rather low input material ( $25 \mu \mathrm{g}$ of peptides) and can be applied to most proteoforms. However, it requires sophisticated LC instrumentation, heavy labeled isotope reference peptides and fraction pooling and might be suboptimal for highly multiplexed workflows. Nonetheless, a direct comparison with established immunoassays (ELISA and Western blotting) found PRISM to be the most sensitive approach. ${ }^{[55]}$ As a consequence, PRISM successfully extends the application range of sensitive and reproducible quantification by SRM to targets that cannot be affinity enriched.

While these target enrichment strategies, if available, increase targeted MS sensitivity, the absence of suitable affinity enrichment methods or limited starting amounts preclude their broad application to all samples. Here, assay sensitivity can only be improved during the MS analysis itself. A couple of intelligent data acquisition methods and data analysis tools have been developed recently that improved both, sensitivity and multiplexing capabilities of targeted MS analysis.

\section{Advanced Targeted MS for Highly Multiplexed Quantitative Analysis}

A main constraint of targeted MS results from the limited number of targets that can be measured per run. While these are still in the 100s for SRM, exploiting the high selectivity of PRM requires long ion accumulation and scan times, dramatically reducing the number of targets per LC-MS run to less than 10. [18-20] A few strategies have been developed to overcome this drawback following two main strategies: retention time adjustment and spike-in triggering acquisition methods. The first approach intends to shorten the targeting windows by adjusting the expected retention time, thereby achieving a more accurate estimation of the actual retention time. The second approach leverages synthetic spike-in reference peptides to efficiently guide MS acquisition of endogenous target peptides in real time.

\subsection{Elution Time Scheduling Approaches}

Elution time scheduling approaches assess the retention time (RT) of target peptides and adjust monitoring windows accordingly. A more accurate assessment of a peptide RT translates into shorter monitoring windows, thereby optimizing the measurement time of the instrument and allowing for a higher number of targets to be measured per run. ${ }^{[12,56]}$ However, RTs are not constant and are affected by chromatographic setups (e.g. buffer composition, flow rate, column condition, sample load, etc.). Therefore, in a scheduled targeted MS analysis, peptide RTs need to be either experimentally determined from previous runs or predicted. Such predictions are based on intrinsic physicochemical properties of the peptides, ${ }^{[57]}$ or on machine learning approaches. ${ }^{[28,58]}$ Software tools such as Skyline have integrated prediction tools (e.g. PROSIT, SSRCal) that enable the design of scheduled approaches. ${ }^{[28,59,60]}$ Nonetheless, these prediction tools are often inexact, as they are incapable of recapitulating chromatographic setups. Alternatively, RTs can be empirically determined, which is costly, time-consuming, and still susceptible to batch-to-batch variation. These variations can be minimized by the use of retention time standards ${ }^{[61,62]}$ that allow the determination of relative peptide elution times that can be easily transferred across LCMS platforms with different LC setups. Based on one preliminary run containing these retention time standards, actual target peptide elution times can be calculated and scheduled.[63] Picky is a useful online tool that provides RT estimations of the target peptides prior to acquisition, based on experimentally determined peptide RTs and fragmentation spectra from the ProteomeTools database. ${ }^{[64,65]}$ Picky comprises a very straightforward method for RT adjustment, however, it is only suitable for human or mouse targets and chromatographic variability during LC-MS analysis cannot be controlled.

By contrast, real-time RT adjustment methods are capable of adjusting scheduled elution time windows during LC-MS analysis and can compensate elution time drifts. Currently, two methods exist that either monitor the elution times of background peptides ${ }^{[66]}$ or specific spike-in standards ${ }^{[62]}$ on the fly and to correct LC deviations in real time. Using these approaches, time windows can be set smaller, in particular when analyzing larger sample batches, increasing overall multiplexing capabilities and minimizing risk of data loss.

\subsection{Spike-in Triggering Acquisition Methods}

Even though elution-time scheduling approaches already considerably increase multiplexing capabilities over traditional SRM/ PRM methods, time windows are still in the low minute range and considerably exceed the actual elution time of the peptide peaks. Conversely, spike-in triggering acquisition methods only start MS acquisition once an abundant and co-eluting reference peptide is detected. Thereby, MS acquisition can be precisely focused and limited to the actual elution time of the target peptide, maximizing multiplexing capabilities. Furthermore, no preliminary LC-MS runs are required to calibrate scheduled elution times and elution time variations during LC-MS analysis do not impact targeted MS analysis. Nonetheless, the implementation of these methods is cumbersome and remains costly, as heavy labelled IS peptides have to be produced and validated.

\subsubsection{SureQuant}

SureQuant is a method adapted from traditional SID-PRM[67] further developed by Thermo and recently implemented on Orbitrap Exploris and Tribrid systems. ${ }^{[68,69]}$ This method eliminates the need for RT scheduling by using spiked-in heavy IS peptides to efficiently guide MS acquisition to the targets of interest (Fig. 3). A SureQuant run toggles between two modes: survey and quantification mode. During the survey mode, a high resolution MS1 scan is acquired to monitor the predefined precursor ion masses of the IS peptides, based on the list of associated $\mathrm{m} / \mathrm{z}$ values and intensity thresholds. If any targeted $\mathrm{m} / \mathrm{z}$ from the inclusion mass list is detected and meets the minimum intensity threshold specified, a fast, low resolution MS2 scan of the IS peptide is performed in the subsequent MS cycle. If the presence of trigger peptides is confirmed by pseudo-spectral matching against pre-selected product ions, quantification mode is triggered, and a high resolution MS2 scan of the endogenous peptide at the defined mass offset is performed with longer fill times to improve measurement sensitivity. A recent study described the targeted analysis of 340 tyrosine-phosphorylated peptides across 31 colorectal cancer tumors using the SureQuant method, and successfully quantified approximately 256 of the targeted endogenous peptides. [69]

As this method does not rely on RT scheduling, it can exploit precious MS time very efficiently, thereby being capable of measuring hundreds of targets in parallel (Fig. 2). However, setting up the method is time consuming, as the heavy peptide ion signals must be determined and optimized. Since the analysis of the endogenous peptide fully relies on the triggering by its heavy IS peptide, the detection of the IS needs to be easy and robust in the samples analyzed. In addition, heavy IS peptides might also suffer from light channel contamination, thereby leading to false 


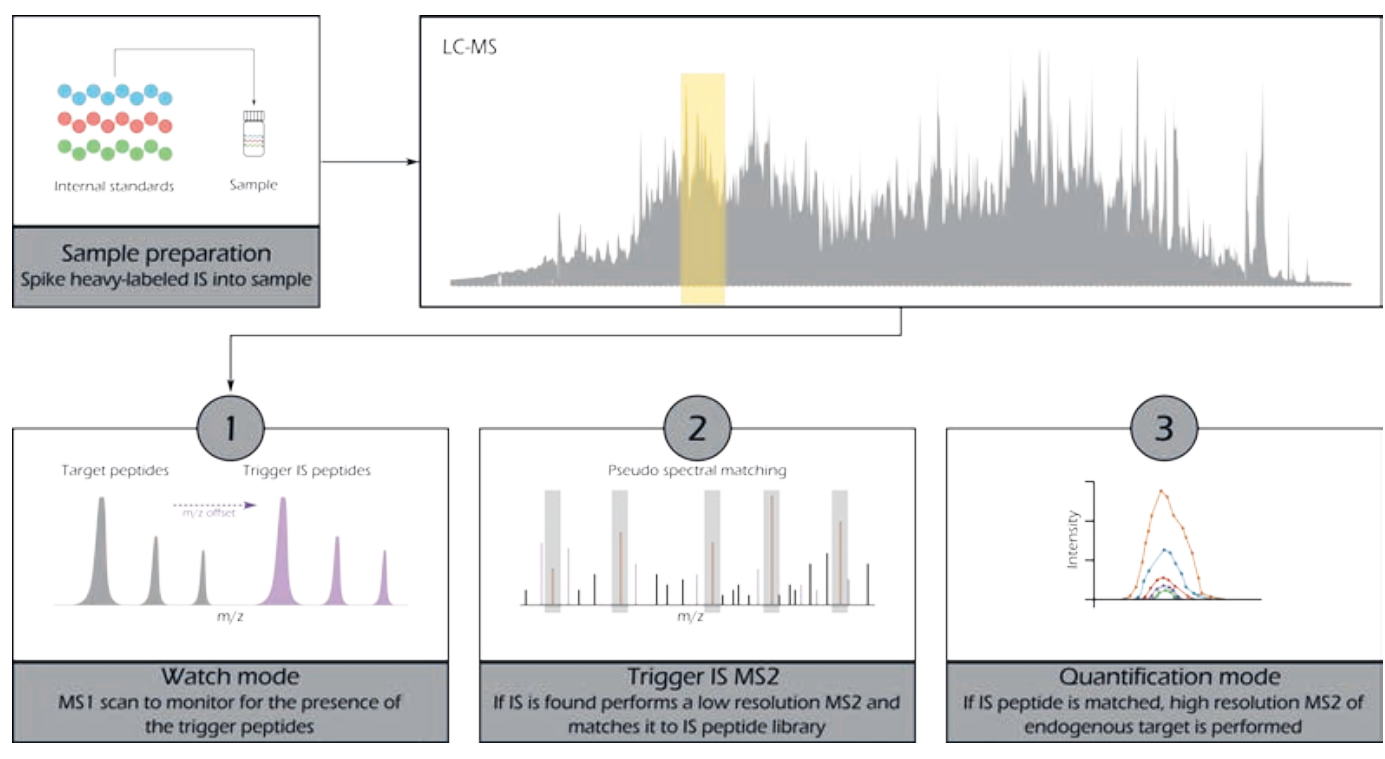

Fig. 3. Schematic representation of the SureQuant methodology. Heavy IS peptides are spiked into the peptide sample before LCMS analysis. The instrument is continuously performing 'survey scans' to search for the presence of IS peptides, combining both MS1 and MS2 analysis. A highresolution MS1 scan is performed to assess the presence of the target peptide using a mass accuracy and intensity filter. If passed, a fast, low resolution MS2 scan of the targeted peptide is triggered and a real-time 'spectrum check' of the fragment ion against reference fragment ions corroborates the identity of the IS peptide. As the standard peptide is co-eluting with its endogenous counterpart, the presence of the IS peptide triggers the MS to switch to a 'quantification mode', thereby enabling high-resolution and sensitive PRM MS analysis for the endogenous peptide.

positive identification of the endogenous peptides. Hence, a pure heavy IS peptide mix should always be included in a SureQuant experiment to control for light impurities.

\subsubsection{TOMAHAQ}

Another spike-in triggering acquisition method is the socalled TOMAHAQ (triggered-by-offset, multiplexed, accuratemass, high-resolution, and absolute quantification) approach. ${ }^{[70]}$ It combines the multiplexing capabilities of the popular tandem mass tag (TMT) protein quantification technology ${ }^{[71]}$ with the high sensitivity of targeted MS.

Here, the trigger peptide does not need to contain heavy stable isotopes since it is labelled with a heavier form of TMT (TMTsh). Like SureQuant, the TMTsh-labelled trigger peptide co-elutes with the corresponding endogenous (TMT-labelled) peptide at an offset mass. Once detected, the TMTsh peptides triggers several scans to first validate the identity of the trigger and target peptide followed by an optimized and sensitive (dwell time up to several seconds) MS3 scan for reporter ion-based quantification. MS3-based quantification offers the advantage of reduced coisolation interference, which is known to hamper TMT reporter ion-based quantification. ${ }^{[72]} \mathrm{A}$ recent study has reported the detection of 520 peptides representative of four major pathways involved in metabolism and inflammation related processes in mice with good correlation to DDA data from fractionated samples. ${ }^{[73]}$

Combining the high (assay) multiplexing capabilities of spike-in triggered targeted MS with the (sample) multiplexing capabilities of TMT, TOMAHAQ provides the highest sample and assay throughput of all targeted MS approaches presented (Fig. 2). In addition, the implemented on-the-fly data analysis to confirm peptide identities before acquiring time-consuming quantification MS scans greatly increases overall confidence and sensitivity of the method.[74,75] Major drawbacks include its restriction to very expensive Tribrid MS systems and its more complex implementation, when compared to SureQuant (Fig. 2), due to the need of TMT labelling and MS3 acquisition. It is important to note that assay setup has been considerably improved by recent software developments. ${ }^{[75]}$ By pooling all peptide fragments for MS3 fragmentation and applying extremely long ion accumulation and scan times, TOMAHAQ also enables very sensitive target analysis down to the low attomole level, however, with an increasing level of signal interferences that are associated with the TMT methodology. [75]

\section{Bioinformatics Data Analysis}

Like all quantitative LC-MS technologies, targeted MS heavily relies on easy to use and reliable software tools for automated data analysis. Compared to discovery LC-MS, targeted MS additionally requires the generation of experiment specific methods using preliminary parameters for the targets of interest that need to be acquired and generated before MS analysis. This is in stark contrast to discovery driven proteome LC-MS analysis that employ the same LC-MS method for certain sample types. These additional assay generation efforts and the necessity to purchase costly heavy IS peptides currently limit the popularity of targeted MS, despite its demonstrated higher quantitative performance and sensitivity over discovery LC-MS workflows.

Targeted MS assay generation largely benefits from ever larger public MS data repositories, ${ }^{[76-80]}$ improved tandem mass predictions ${ }^{[28,81]}$ as well as the increasing generation and availability of validated targeted MS assays. ${ }^{[82]}$ Once set up for a specific protein, the corresponding targeted peptide assays and heavy IS can be used across LC-MS platforms, samples and laboratories for all future quantitative analyses of this particular protein. ${ }^{[24]}$ Being only a one-time effort, targeted MS assays should eventually be available for all proteins expressed in the most relevant organisms. Along these lines, thorough efforts have been undertaken recently to generate targeted MS assays on an organism wide scale for yeast ${ }^{[83]}$ and human proteins. ${ }^{[84]}$ Albeit highly useful, a full and standardized validation of most of these assays to efficiently detect and accurately quantify their endogenous target proteins is still missing, considerably limiting their general application.

Furthermore, there is still a lot of work to be done to facilitate the entire targeted MS workflow and make it usable for the masses. This mainly relates to improvements on the informatics side. Tools such as Picky[64] greatly simplify assay generation and should be extended by additional organisms and validated targeted MS assays including heavy IS peptide availabilities. Also, most data acquisition software controlling high-resolution MS instruments that are capable of advanced PRM workflows, like 
SureQuant, do not support these. This should be improved to make these technologies available to most proteomics laboratories. For quantitative data analysis an excellent free tool, Skyline, ${ }^{[85]}$ exists that supports the entire SRM, PRM and SWATH workflow including the final data analysis. However, for many PRM and SRM assays, automatic peak integration remains challenging and time-consuming manual validation is often required for proper quantification. Probabilistic peak scoring algorithms have already been developed ${ }^{[86,87]}$ and should be further improved and implemented into this popular software suite to minimize hands-on data analysis time. To conclude, further software adjustments and developments are required to streamline and automatize the entire targeted MS workflow. As long as this is not available, targeted MS will remain a tool for specific laboratories only.

\section{Conclusions}

With its possibility to measure proteoforms, proteomics provides more functionally and clinically relevant data compared to genomics, and can considerably contribute to a better understanding of molecular disease mechanisms and biomedical research. Compared to transcriptomics, the main obstacle of LC-MS based proteomics for clinical applications results from its relatively low sample throughput and low proteome coverage. A lot of progress has been made in this regard over the last years combining ion mobility or intelligent workflows with SWATH, greatly reducing analysis time with unchanged proteome coverage. ${ }^{[88,89]}$ Despite these efforts, LC-MS analysis cannot be parallelized and thus will never reach the throughput of currently employed parallelizable screening technologies. This is also the reason for the continued interest in developing totally different array based quantitative proteomics technologies, ${ }^{[90]}$ some of them are already capable to analyzing a few thousand (mostly human) proteins. Numbers will certainly further increase in the near future, however, since most of these technologies rely on specifically developed assays, it will be a nearly impossible task, also commercially, to expand the analysis to the entire kingdom of life and to all proteoforms. Conversely, LC-MS analysis can be applied to any protein and capture any modification that alters peptide or protein masses. It can even be applied to determine changes in protein structure that are closely related to protein function. ${ }^{[91,92]}$ Therefore, LC-MS based proteomics is well suited, also for the future, to provide essential information to better understand life. SRM assays have already been demonstrated to be of sufficient dynamic range, reproducibility and sensitivity, also across laboratories, to be suited for many clinical screens. ${ }^{[24]}$ Recent trigger based targeted MS approaches, like SureQuant and TOMAHAQ, reach similar or even higher assay throughput while having superior selectivity and dynamic quantification ranges within complex human cell samples over SRM assays (Fig. 2, Table 1). Even though more efforts are required for method setup, the generated assays can be employed for all future targeted MS analysis without any adjustments. Several assays have been combined to screen entire signaling pathways or plasma biomarkers with high sensitivities and confidence. ${ }^{[45,68-70]} \mathrm{We}$ are therefore convinced that these advanced and easy to apply targeted MS approaches can provide the required sample throughput and dynamic range to cover targets inaccessible or below the detection limit of currently employed quantitative assays, greatly enlarging application possibilities in biological, clinical and biomedical research.

Received: October 31, 2021

[1] R. Aebersold, M. Mann, Nature 2016, 537, 347, https://doi.org/10.1038/nature19949.

[2] E. L. Huttlin, R. J. Bruckner, J. A. Paulo, J. R. Cannon, L. Ting, K. Baltier, G. Colby, F. Gebreab, M. P. Gygi, H. Parzen, J. Szpyt, S. Tam, G. Zarraga, L. Pontano-Vaites, S. Swarup, A. E. White, D. K. Schweppe, R. Rad, B. K. Erickson, R. A. Obar, K. G. Guruharsha, K. Li, S.
Artavanis-Tsakonas, S. P. Gygi, J. W. Harper, Nature 2017, 545, 505, https://doi.org/10.1038/nature22366.

[3] I. Cima, R. Schiess, P. Wild, M. Kaelin, P. Schüffler, V. Lange, P. Picotti, R. Ossola, A. Templeton, O. Schubert, T. Fuchs, T. Leippold, S. Wyler, J. Zehetner, W. Jochum, J. Buhmann, T. Cerny, H. Moch, S. Gillessen, R. Aebersold, W. Krek, Proc. Natl. Acad. Sci. USA 2011, 108, 3342, https://doi.org/10.1073/pnas.1013699108.

[4] H. Keshishian, M. W. Burgess, M. A. Gillette, P. Mertins, K. R. Clauser, D. R. Mani, E. W. Kuhn, L. A. Farrell, R. E. Gerszten, S. A. Carr, Mol. Cell Proteomics 2015, 14, 2375, https://doi.org/10.1074/mcp.m114.046813.

[5] M. Tognetti, K. Sklodowski, S. Müller, D. Kamber, J. Muntel, R. Bruderer, L. Reiter, Biorxiv 2021, 2021.10.05.463153, https://doi.org/10.1101/2021.10.05.463153.

[6] N. CPTAC, P. Mertins, D. R. Mani, K. V. Ruggles, M. A. Gillette, K. R. Clauser, P. Wang, X. Wang, J. W. Qiao, S. Cao, F. Petralia, E. Kawaler, F. Mundt, K. Krug, Z. Tu, J. T. Lei, M. L. Gatza, M. Wilkerson, C. M. Perou, V. Yellapantula, K. Huang, C. Lin, M. D. McLellan, P. Yan, S. R. Davies, R. R. Townsend, S. J. Skates, J. Wang, B. Zhang, C. R. Kinsinger, M. Mesri, H. Rodriguez, L. Ding, A. G. Paulovich, D. Fenyö, M. J. Ellis, S. A. Carr, Nature 2016, 534, 55, https://doi.org/10.1038/nature18003.

[7] M. M. S. Obradović, B. Hamelin, N. Manevski, J. P. Couto, A. Sethi, M.-M. Coissieux, S. Münst, R. Okamoto, H. Kohler, A. Schmidt, M. Bentires-Alj, Nature 2019, 567, 540, https://doi.org/10.1038/s41586-019-1019-4.

[8] P. Picotti, R. Aebersold, Nat. Methods 2012, 9, 555, https://doi.org/10.1038/ nmeth. 2015 .

[9] L. C. Gillet, P. Navarro, S. Tate, H. Röst, N. Selevsek, L. Reiter, R. Bonner, R. Aebersold, Mol. Cell Proteomics 2012, 11, O111.016717, https://doi.org/10.1074/mcp.o111.016717.

[10] R. Schiess, B. Wollscheid, R. Aebersold, Mol. Oncol. 2009, 3, 33, https://doi.org/10.1016/j.molonc.2008.12.001.

[11] J. D. Venable, M.-Q. Dong, J. Wohlschlegel, A. Dillin, J. R. Yates, Nat. Methods 2004, 1, 39, https://doi.org/10.1038/nmeth705.

[12] V. Lange, P. Picotti, B. Domon, R. Aebersold, Mol. Syst. Biol. 2008, 4, 222, https://doi.org/10.1038/msb.2008.61

[13] A. Wolf-Yadlin, S. Hautaniemi, D. A. Lauffenburger, F. M. White, Proc. Natl. Acad. Sci. USA 2007, 104, 5860, https://doi.org/10.1073/pnas.0608638104.

[14] H. Keshishian, T. Addona, M. Burgess, E. Kuhn, S. A. Carr, Mol. Cell. Proteomics 2007, 6, 2212, https://doi.org/10.1074/mcp.m700354-mcp200.

[15] A. C. Peterson, J. D. Russell, D. J. Bailey, M. S. Westphall, J. J. Coon, Mol. Cell. Proteomics 2012, 11, 1475, https://doi.org/10.1074/mcp.o112.020131.

[16] S. Gallien, E. Duriez, C. Crone, M. Kellmann, T. Moehring, B. Domon, Mol. Cell Proteomics 2012, 11, 1709, https://doi.org/10.1074/mcp.o112.019802.

[17] R. Bruderer, O. M. Bernhardt, T. Gandhi, S. M. Miladinović, L.-Y. Cheng, S. Messner, T. Ehrenberger, V. Zanotelli, Y. Butscheid, C. Escher, O. Vitek, O. Rinner, L. Reiter, Mol. Cell. Proteomics 2015, 14, 1400, https://doi.org/10.1074/mcp.m114.044305.

[18] A. Schmidt, H. Farine, M. P. Keller, A. Sebastian, L. Kozera, R. W. D. Welford, D. S. Strasser, J. Proteome Res. 2020, 19, 4196, https://doi.org/10.1021/acs.jproteome.0c00494.

[19] C. Arquint, F. Cubizolles, A. Morand, A. Schmidt, E. A. Nigg, Open Biol. 2018, 8, 170253, https://doi.org/10.1098/rsob.170253.

[20] C. D. L. Nguyen, S. Malchow, S. Reich, S. Steltgens, K. V. Shuvaev, S. Loroch, C. Lorenz, A. Sickmann, C. B. Knobbe-Thomsen, B. Tews, J. Medenbach, R. Ahrends, Sci. Rep.-UK 2019, 9, 8836, https://doi.org/10.1038/s41598-019-45237-5.

[21] P. Picotti, B. Bodenmiller, L. N. Mueller, B. Domon, R. Aebersold, Cell 2009, 138, 795, https://doi.org/10.1016/j.cell.2009.05.051.

[22] S. A. Gerber, J. Rush, O. Stemman, M. W. Kirschner, S. P. Gygi, Proc. Natl. Acad. Sci. USA 2003, 100, 6940, https://doi.org/10.1073/pnas.0832254100.

[23] M. Bauer, E. Ahrné, A. P. Baron, T. Glatter, L. L. Fava, A. Santamaria, E. A. Nigg, A. Schmidt, J. Proteome Res 2014, 13, 5973, https://doi.org/10.1021/pr500860c.

[24] T. A. Addona, S. E. Abbatiello, B. Schilling, S. J. Skates, D. R. Mani, D. M. Bunk, C. H. Spiegelman, L. J. Zimmerman, A.-J. L. Ham, H Keshishian, S. C. Hall, S. Allen, R. K. Blackman, C. H. Borchers, C. Buck, H. L. Cardasis, M. P. Cusack, N. G. Dodder, B. W. Gibson, J. M. Held, T. Hiltke, A. Jackson, E. B. Johansen, C. R. Kinsinger, J. Li, M. Mesri, T. A. Neubert, R. K. Niles, T. C. Pulsipher, D. Ransohoff, H. Rodriguez, P. A. Rudnick, D. Smith, D. L. Tabb, T. J. Tegeler, A. M. Variyath, L. J. Vega-Montoto, A. Wahlander, S. Waldemarson, M. Wang, J. R. Whiteaker, L. Zhao, N. L. Anderson, S. J. Fisher, D. C. Liebler, A. G. Paulovich, F. E. Regnier, P. Tempst, S. A. Carr, Nat. Biotechnol. 2009, 27, 633, https://doi.org/10.1038/nbt.1546.

[25] R. Bruderer, O. M. Bernhardt, T. Gandhi, Y. Xuan, J. Sondermann, M. Schmidt, D. Gomez-Varela, L. Reiter, Mol. Cell. Proteomics 2017, 16, 2296, https://doi.org/10.1074/mcp.ra117.000314.

[26] B. C. Searle, L. K. Pino, J. D. Egertson, Y. S. Ting, R. T. Lawrence, B. X. MacLean, J. Villén, M. J. MacCoss, Nat. Commun. 2018, 9, 5128 , https://doi.org/10.1038/s41467-018-07454-w.

[27] B. C. Searle, K. E. Swearingen, C. A. Barnes, T. Schmidt, S. Gessulat, B. Kuster, M. Wilhelm, Nat. Commun. 2020, 11, 1548 , https://doi.org/10.1038/s41467-020-15346-1 
[28] S. Gessulat, T. Schmidt, D. P. Zolg, P. Samaras, K. Schnatbaum, J. Zerweck, T. Knaute, J. Rechenberger, B. Delanghe, A. Huhmer, U. Reimer, H.-C. Ehrlich, S. Aiche, B. Kuster, M. Wilhelm, Nat. Methods 2019, 16, 509, https://doi.org/10.1038/s41592-019-0426-7.

[29] A. Martinez-Val, D. B. Bekker-Jensen, A. Hogrebe, J. V. Olsen, Meth. Mol. Biol. 2021, 2361, 95, https://doi.org/10.1007/978-1-0716-1641-3 6.

[30] C.-C. Tsou, D. Avtonomov, B. Larsen, M. Tucholska, H. Choi, A.-C. Gingras, A. I. Nesvizhskii, Nat. Methods 2015, https://doi.org/10.1038/nmeth.3255.

[31] C. D. Kelstrup, K. Aizikov, T. S. Batth, A. Kreutzman, D. Grinfeld, O. Lange, D. Mourad, A. A. Makarov, J. V. Olsen, J. Proteome Res. 2018, 17, 4008, https://doi.org/10.1021/acs.jproteome.8b00381.

[32] R. Bruderer, O. M. Bernhardt, T. Gandhi, Y. Xuan, J. Sondermann, M. Schmidt, D. Gomez-Varela, L. Reiter, Mol. Cell. Proteomics 2017, mcp. M116.065730, https://doi.org/10.1074/mcp.m116.065730.

[33] B. C. Collins, C. L. Hunter, Y. Liu, B. Schilling, G. Rosenberger, S. L. Bader, D. W. Chan, B. W. Gibson, A.-C. Gingras, J. M. Held, M. Hirayama-Kurogi, G. Hou, C. Krisp, B. Larsen, L. Lin, S. Liu, M. P. Molloy, R. L. Moritz, S. Ohtsuki, R. Schlapbach, N. Selevsek, S. N. Thomas, S.-C. Tzeng, H. Zhang, R. Aebersold, Nat. Commun. 2017, 8, 291 , https://doi.org/10.1038/s41467-017-00249-5.

[34] C. D. Kelstrup, D. B. Bekker-Jensen, T. N. Arrey, A. Hogrebe, A. Harder, J. V. Olsen, J. Proteome Res. 2017, https://doi.org/10.1021/acs.jproteome.7b00602.

[35] N. L. Anderson, N. G. Anderson, L. R. Haines, D. B. Hardie, R. W. Olafson, T. W. Pearson, J. Proteome Res. 2004, 3, 235, https://doi.org/10.1021/pr034086h.

[36] J. R. Whiteaker, L. Zhao, L. Anderson, A. G. Paulovich, Mol. Cell. Proteomics 2010, 9, 184, https://doi.org/10.1074/mcp.m900254-mcp200.

[37] T. Shi, D. Su, T. Liu, K. Tang, D. G. Camp, W.-J. Qian, R. D. Smith, Proteomics 2012, 12, 1074, https://doi.org/10.1002/pmic.201100436.

[38] T. Katafuchi, D. Esterházy, A. Lemoff, X. Ding, V. Sondhi, S. A. Kliewer, H. Mirzaei, D. J. Mangelsdorf, Cell. Metab. 2015, 21, 898, https://doi.org/10.1016/j.cmet.2015.05.004.

[39] J. R. Whiteaker, L. Zhao, C. Frisch, F. Ylera, S. Harth, A. Knappik, A. G. Paulovich, J. Proteome Res. 2014, 13, 2187, https://doi.org/10.1021/pr4009404.

[40] K. K. Mangalaparthi, S. Chavan, A. K. Madugundu, S. Renuse, P. M. Vanderboom, A. D. Maus, J. Kemp, B. R. Kipp, S. K. Grebe, R. J. Singh, A. Pandey, Clin. Proteom. 2021, 18, 25, https://doi.org/10.1186/s12014-021-09331-z.

[41] J. R. Whiteaker, L. Zhao, C. Lin, P. Yan, P. Wang, A. G. Paulovich, Mol. Cell. Proteomics 2012, 11, M111.015347, https://doi.org/10.1074/mcp.m111.015347.

[42] Y. Zhao, S. G. Widen, M. Jamaluddin, B. Tian, T. G. Wood, C. B. Edeh, A. R. Brasier, Mol. Cell. Proteomics 2011, 10, M111.008771, https://doi.org/10.1074/mcp.m111.008771.

[43] B. Krastins, A. Prakash, D. A. Sarracino, D. Nedelkov, E. E. Niederkofler, U. A. Kiernan, R. Nelson, M. S. Vogelsang, G. Vadali, A. Garces, J. N. Sutton, S. Peterman, G. Byram, B. Darbouret, J. R. Pérusse, N. G. Seidah, B. Coulombe, J. Gobom, E. Portelius, J. Pannee, K. Blennow, V. Kulasingam, L. Couchman, C. Moniz, M. F. Lopez, Clin. Biochem. 2013, 46, 399, https://doi.org/10.1016/j.clinbiochem.2012.12.019.

[44] K. Carbonara, M. Andonovski, J. R. Coorssen, Proteomes 2021, 9, 38, https://doi.org/10.3390/proteomes 9030038

[45] H. Keshishian, E. R. McDonald, F. Mundt, R. Melanson, K. Krug, D. A. Porter, L. Wallace, D. Forestier, B. Rabasha, S. E. Marlow, J. Jane-Valbuena, E. Todres, H. Specht, M. L. Robinson, P. M. J. Beltran, O. Babur, M. E. Olive, J. Golji, E. Kuhn, M. Burgess, M. A. MacMullan, T. Rejtar, K. Wang, D. Mani, S. Satpathy, M. A. Gillette, W. R. Sellers, S. A. Carr, Mol. Syst. Biol. 2021, 17, https://doi.org/10.15252/msb.202010156.

[46] T. Shi, E. Song, S. Nie, K. D. Rodland, T. Liu, W.-J. Qian, R. D. Smith, Proteomics 2016, 16, 2160, https://doi.org/10.1002/pmic.201500449.

[47] J. Simicevic, A. W. Schmid, P. A. Gilardoni, B. Zoller, S. K. Raghav, I. Krier, C. Gubelmann, F. Lisacek, F. Naef, M. Moniatte, B. Deplancke, Nat. Methods 2013, https://doi.org/10.1038/nmeth.2441

[48] G. Such-Sanmartín, N. Bache, A. K. Callesen, A. RogowskaWrzesinska, O. N. Jensen, J. Proteomics 2015, 113, 29, https://doi.org/10.1016/j.jprot.2014.09.013.

[49] J. E. Blume, W. C. Manning, G. Troiano, D. Hornburg, M. Figa, L. Hesterberg, T. L. Platt, X. Zhao, R. A. Cuaresma, P. A. Everley, M. Ko, H. Liou, M. Mahoney, S. Ferdosi, E. M. Elgierari, C. Stolarczyk, B. Tangeysh, H. Xia, R. Benz, A. Siddiqui, S. A. Carr, P. Ma, R. Langer, V. Farias, O. C. Farokhzad, Nat. Commun. 2020, 11, 3662, https://doi.org/10.1038/s41467-020-17033-7.

[50] T. Shi, Y. Gao, M. J. Gaffrey, C. D. Nicora, T. L. Fillmore, W. B. Chrisler, M. A. Gritsenko, C. Wu, J. He, K. J. Bloodsworth, R. Zhao, D. G. Camp, T. Liu, K. D. Rodland, R. D. Smith, H. S. Wiley, W.-J. Qian, Anal. Chem. 2015, 87, 1103, https://doi.org/10.1021/ac503797x

[51] Z. Tan, J. Zhu, P. M. Stemmer, L. Sun, Z. Yang, K. Schultz, M. J. Gaffrey, A. J. Cesnik, X. Yi, X. Hao, M. R. Shortreed, T. Shi, D. M. Lubman, J. Proteome Res. 2020, 19, 1635, https://doi.org/10.1021/acs.jproteome.9b00840.
[52] T. Shi, T. L. Fillmore, X. Sun, R. Zhao, A. A. Schepmoes, M. Hossain, F. Xie, S. Wu, J.-S. Kim, N. Jones, R. J. Moore, L. Pasa-Tolić, J. Kagan, K. D. Rodland, T. Liu, K. Tang, D. G. Camp, R. D. Smith, W.-J. Qian, Proc. Natl. Acad. Sci. USA 2012, 109, 15395, https://doi.org/10.1073/pnas.1204366109.

[53] Y. Wang, F. Yang, M. A. Gritsenko, Y. Wang, T. Clauss, T. Liu, Y. Shen, M. E. Monroe, D. López-Ferrer, T. Reno, R. J. Moore, R. L. Klemke, D. G. Camp, R. D. Smith, Proteomics 2011, 11, 2019 , https://doi.org/10.1002/pmic.201000722.

[54] T. Shi, X. Sun, Y. Gao, T. L. Fillmore, A. A. Schepmoes, R. Zhao, J. He, R. J. Moore, J. Kagan, K. D. Rodland, T. Liu, A. Y. Liu, R. D. Smith, K. Tang, D. G. Camp, W.-J. Qian, J. Proteome Res. 2013, 12, 3353 , https://doi.org/10.1021/pr400178v

[55] J. He, A. A. Schepmoes, T. Shi, C. Wu, T. L. Fillmore, Y. Gao, R. D. Smith, W.-J. Qian, K. D. Rodland, T. Liu, D. G. Camp, A. Rastogi, S.-H. Tan, W. Yan, A. A. Mohamed, W. Huang, S. Banerjee, J. Kagan, S. Srivastava, D. G. McLeod, S. Srivastava, G. Petrovics, A. Dobi, A. Srinivasan, J. Transl. Med. 2015, 13, 54, https://doi.org/10.1186/s12967-015-0418-z.

[56] V. Lange, J. A. Malmström, J. Didion, N. L. King, B. P. Johansson, J. Schäfer, J. Rameseder, C.-H. Wong, E. W. Deutsch, M.-Y. Brusniak, P. Bühlmann, L. Björck, B. Domon, R. Aebersold, Mol. Cell. Proteomics 2008, 7, 1489, https://doi.org/10.1074/mcp.m800032-mcp200.

[57] V. Spicer, A. Yamchuk, J. Cortens, S. Sousa, W. Ens, K. G. Standing, J. A. Wilkins, O. V. Krokhin, Anal. Chem. 2007, 79, 8762, https://doi.org/10.1021/ac071474k.

[58] C. Ma, Y. Ren, J. Yang, Z. Ren, H. Yang, S. Liu, Anal. Chem. 2018, 90, 10881, https://doi.org/10.1021/acs.analchem.8b02386.

[59] L. K. Pino, B. C. Searle, J. G. Bollinger, B. Nunn, B. MacLean, M. J. MacCoss, Mass Spectrom. Rev. 2020, 39, 229, https://doi.org/10.1002/mas.21540.

[60] O. V. Krokhin, R. Craig, V. Spicer, W. Ens, K. G. Standing, R. C. Beavis, J. A. Wilkins, Mol. Cell. Proteomics 2004, 3, 908 , https://doi.org/10.1074/mcp.m400031-mcp200.

[61] H. Mirzaei, M.-Y. Brusniak, L. N. Mueller, S. Letarte, J. D. Watts, R. Aebersold, Mol. Cell. Proteomics 2009, 8, 1934, https://doi.org/10.1074/mcp.m800569-mcp200.

[62] C. Escher, L. Reiter, B. MacLean, R. Ossola, F. Herzog, J. Chilton, M. J. MacCoss, O. Rinner, Proteomics 2012, 12, 1111 , https://doi.org/10.1002/pmic.201100463.

[63] Y. Xiao, L. Guo, Y. Wang, Mol. Cell. proteomics 2014 https://doi.org/10.1074/mcp.m113.036905.

[64] H. Zauber, M. Kirchner, M. Selbach, Nat. Methods 2018, 15, 156, https://doi.org/10.1038/nmeth.4607.

[65] D. P. Zolg, M. Wilhelm, K. Schnatbaum, J. Zerweck, T. Knaute, B. Delanghe, D. J. Bailey, S. Gessulat, H.-C. Ehrlich, M. Weininger, P. Yu, J. Schlegl, K. Kramer, T. Schmidt, U. Kusebauch, E. W. Deutsch, R. Aebersold, R. L. Moritz, H. Wenschuh, T. Moehring, S. Aiche, A. Huhmer, U. Reimer, B. Kuster, Nat. Methods 2017, 14, 259, https://doi.org/10.1038/nmeth.4153.

[66] C. Wichmann, F. Meier, S. V. Winter, A.-D. Brunner, J. Cox, M. Mann, Mol. Cell. Proteomics 2019, 18, 982, https://doi.org/10.1074/mcp.tir118.001131.

[67] S. Gallien, S. Y. Kim, B. Domon, Mol. Cell. Proteomics 2015, 14, 1630 https://doi.org/10.1074/mcp.o114.043968.

[68] L. E. Stopfer, A. S. Gajadhar, B. Patel, S. Gallien, D. T. Frederick, G. M Boland, R. J. Sullivan, F. M. White, Proc. Natl. Acad. Sci. USA 2021, 118 , e2111173118, https://doi.org/10.1073/pnas.2111173118.

[69] L. E. Stopfer, C. T. Flower, A. S. Gajadhar, B. Patel, S. Gallien, D. Lopez-Ferrer, F. M. White, Cancer Res. 2021, 81, 2495, https://doi.org/10.1158/0008-5472.can-20-3804.

[70] B. K. Erickson, C. M. Rose, C. R. Braun, A. R. Erickson, J. Knott, G. C. McAlister, M. Wühr, J. A. Paulo, R. A. Everley, S. P. Gygi, Mol. Cell. 2016 , 65, 361, https://doi.org/10.1016/j.molcel.2016.12.005.

[71] A. Thompson, J. Schäfer, K. Kuhn, S. Kienle, J. Schwarz, G. Schmidt, T. Neumann, R. Johnstone, A. K. A. Mohammed, C. Hamon, Anal. Chem. 2003, 75, 1895, https://doi.org/10.1021/ac0262560.

[72] L. Ting, R. Rad, S. P. Gygi, W. Haas, Nat. Methods 2011, 8, 937, https://doi.org/10.1038/nmeth.1714.

[73] Q. Yu, H. Xiao, M. P. Jedrychowski, D. K. Schweppe, J. Navarrete-Perea, J. Knott, J. Rogers, E. T. Chouchani, S. P. Gygi, Proc. Natl. Acad. Sci. USA 2020, 117, 9723, https://doi.org/10.1073/pnas.1919410117.

[74] F. Liu, K. Singhal, R. Matney, S. Acharya, C. A. Akdis, K. C. Nadeau, A. S. Chien, R. D. Leib, Proteomics 2020, 20, 1900105, https://doi.org/10.1002/pmic.201900105

[75] C. M. Rose, B. K. Erickson, D. K. Schweppe, R. Viner, J. Choi, J. Rogers, R. Bomgarden, S. P. Gygi, D. S. Kirkpatrick, J. Proteome Res. 2018, 18, 594, https://doi.org/10.1021/acs.jproteome.8b00767.

[76] Y. Perez-Riverol, A. Csordas, J. Bai, M. Bernal-Llinares, S. Hewapathirana, D. J. Kundu, A. Inuganti, J. Griss, G. Mayer, M. Eisenacher, E. Pérez, J. Uszkoreit, J. Pfeuffer, T. Sachsenberg, S. Yilmaz, S. Tiwary, J. Cox, E. Audain, M. Walzer, A. F. Jarnuczak, T. Ternent, A. Brazma, J. A. Vizcaíno, Nucl. Acids Res. 2019, 47, D442, https://doi.org/10.1093/nar/gky1106. 
[77] M. Choi, J. Carver, C. Chiva, M. Tzouros, T. Huang, T.-H. Tsai, B. Pullman, O. M. Bernhardt, R. Hüttenhain, G. C. Teo, Y. Perez-Riverol, J. Muntel, M. Müller, S. Goetze, M. Pavlou, E. Verschueren, B. Wollscheid, A. I. Nesvizhskii, L. Reiter, T. Dunkley, E. Sabido, N. Bandeira, O. Vitek, Nat. Methods 2020, 334, 1226, https://doi.org/10.1038/s41592-020-0955-0.

[78] P. Samaras, T. Schmidt, M. Frejno, S. Gessulat, M. Reinecke, A. Jarzab, J. Zecha, J. Mergner, P. Giansanti, H.-C. Ehrlich, S. Aiche, J. Rank, H. Kienegger, H. Krcmar, B. Kuster, M. Wilhelm, Nucl. Acids Res. 2019, 509, 582, https://doi.org/10.1093/nar/gkz974.

[79] F. Desiere, E. W. Deutsch, N. L. King, A. I. Nesvizhskii, P. Mallick, J. Eng, S. Chen, J. Eddes, S. N. Loevenich, R. Aebersold, Nucl. Acids Res. 2006, 34 D655, https://doi.org/10.1093/nar/gkj040.

[80] C. Schaab, T. Geiger, G. Stoehr, J. Cox, M. Mann, Mol. Cell. Proteomics 2012, 11, M111.014068, https://doi.org/10.1074/mcp.m111.014068.

[81] S. Tiwary, R. Levy, P. Gutenbrunner, F. S. Soto, K. K. Palaniappan, L. Deming, M. Berndl, A. Brant, P. Cimermančič, J. Cox, Nat. Methods 2019. 16, 519, https://doi.org/10.1038/s41592-019-0427-6.

[82] J. R. Whiteaker, G. N. Halusa, A. N. Hoofnagle, V. Sharma, B. MacLean, P. Yan, J. A. Wrobel, J. Kennedy, D. R. Mani, L. J. Zimmerman, M. R. Meyer, M. Mesri, H. Rodriguez, S. E. Abbatiello, E. Boja, S. A. Carr, D. W. Chan, X. Chen, J. Chen, S. R. Davies, M. J. C. Ellis, D. Fenyö, T. Hiltke, K. A. Ketchum, C. Kinsinger, E. Kuhn, D. C. Liebler, D. Lin, T. Liu, M. Loss, M. J. MacCoss, W.-J. Qian, R. Rivers, K. D. Rodland, K. V. Ruggles, M. G. Scott, R. D. Smith, S. Thomas, R. R. Townsend, G. Whiteley, C Wu, H. Zhang, Z. Zhang, A. G. Paulovich, Nat. Methods 2014, 11, 703, https://doi.org/10.1038/nmeth.3002.

[83] P. Picotti, H. Lam, D. Campbell, E. W. Deutsch, H. Mirzaei, J. Ranish, B. Domon, R. Aebersold, Nat. Methods 2008, 5, 913, https://doi.org/10.1038/nmeth1108-913.

[84] U. Kusebauch, D. S. Campbell, E. W. Deutsch, C. S. Chu, D. A. Spicer, M.Y. Brusniak, J. Slagel, Z. Sun, J. Stevens, B. Grimes, D. Shteynberg, M. R. Hoopmann, P. Blattmann, A. V. Ratushny, O. Rinner, P. Picotti, C. Carapito, C.-Y. Huang, M. Kapousouz, H. Lam, T. Tran, E. Demir, J. D. Aitchison, C. Sander, L. Hood, R. Aebersold, R. L. Moritz, Cell 2016, 166, 766, https://doi.org/10.1016/j.cell.2016.06.041.

[85] B. Maclean, D. M. Tomazela, N. Shulman, M. Chambers, G. L. Finney, B. Frewen, R. Kern, D. L. Tabb, D. C. Liebler, M. J. Maccoss, Bioinform. 2010, 26, 966, https://doi.org/10.1093/bioinformatics/btq054.

[86] L. Reiter, O. Rinner, P. Picotti, R. Hüttenhain, M. Beck, M.-Y Brusniak, M. O. Hengartner, R. Aebersold, Nat. Methods 2011, 8, 430, https://doi.org/10.1038/nmeth.1584.
[87] S. E. Abbatiello, D. R. Mani, H. Keshishian, S. A. Carr, Clin. Chem. 2010, 56, 291, https://doi.org/10.1373/clinchem.2009.138420.

[88] F. Meier, S. Beck, N. Grassl, M. Lubeck, M. A. Park, O. Raether, M. Mann, J. Proteome Res. 2015, https://doi.org/10.1021/acs.jproteome.5b00932.

[89] C. B. Messner, V. Demichev, N. Bloomfield, J. S. L. Yu, M. White, M. Kreidl, A.-S. Egger, A. Freiwald, G. Ivosev, F. Wasim, A Zelezniak, L. Jürgens, N. Suttorp, L. E. Sander, F. Kurth, K. S. Lilley, M. Mülleder, S. Tate, M. Ralser, Nat. Biotechnol. 2021, 39, 846 , https://doi.org/10.1038/s41587-021-00860-4.

[90] J. A. Alfaro, P. Bohländer, M. Dai, M. Filius, C. J. Howard, X. F. van Kooten, S. Ohayon, A. Pomorski, S. Schmid, A. Aksimentiev, E. V. Anslyn, G. Bedran, C. Cao, M. Chinappi, E. Coyaud, C. Dekker, G. Dittmar, N. Drachman, R. Eelkema, D. Goodlett, S. Hentz, U. Kalathiya, N. L. Kelleher, R. T. Kelly, Z. Kelman, S. H. Kim, B. Kuster, D. RodriguezLarrea, S. Lindsay, G. Maglia, E. M. Marcotte, J. P. Marino, C. Masselon, M. Mayer, P. Samaras, K. Sarthak, L. Sepiashvili, D. Stein, M. Wanunu, M. Wilhelm, P. Yin, A. Meller, C. Joo, Nat. Methods 2021, 18, 604 https://doi.org/10.1038/s41592-021-01143-1.

[91] Y. Feng, G. D. Franceschi, A. Kahraman, M. Soste, A. Melnik, P. J. Boersema P. P. de Laureto, Y. Nikolaev, A. P. Oliveira, P. Picotti, Nat. Biotechnol. 2014 32, 1036, https://doi.org/10.1038/nbt.2999.

[92] M. M. Savitski, F. B. M. Reinhard, H. Franken, T. Werner, M. F. Savitski, D. Eberhard, D. M. Molina, R. Jafari, R. B. Dovega, S. Klaeger, B. Kuster, P. Nordlund, M. Bantscheff, G. Drewes, Science 2014, 346, 1255784 , https://doi.org/10.1126/science.1255784.

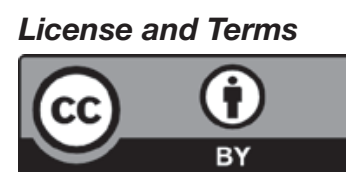

This is an Open Access article under the terms of the Creative Commons Attribution License CC BY 4.0. The material may not be used for commercial purposes.

The license is subject to the CHIMIA terms and conditions: (https://chimia.ch/chimia/about).

The definitive version of this article is the electronic one that can be found at https://doi.org/10.2533/chimia.2022.81 